\title{
In Silico Study to Predict the Potential of Beta Asarone, Methyl Piperonylketone, Coumaric Acid in Piper Crocatum as Anticancer Agents
}

\author{
Ahmed Hasan Abkar*, Moch. Sasmito Djati², Widodo \\ Department of Biology, Faculty of Mathematics and Natural Sciences, University of Brawijaya, Malang, Indonesia \\ Abstract
}

Piper Crocatum Ruiz \& Pav leaves often be used to treat various diseases, including cancer, empirically. This study aimed to analyze the anticancer activities of Piper Crocatum bioactive compounds via In Silico analysis. The methods were biological activity analysis, cell line cytotoxicity activity, SwisSADME, STITCH, molecular docking, and molecular dynamics simulation. The investigated bioactive compounds were $\beta$-asarone, methyl piperonylketone, and coumaric acid. The results showed the biological activities of the compounds related to anticancer were anti-mutagenic, TNF expression inhibitive, and MMP9 expression inhibitive. The prediction of cytotoxicity analysis results showed that investigated bioactive compounds were toxic on various tumor cell lines. Based on swissADME results, almost all compounds have good pharmacological properties, except coumaric acid. Docking analysis demonstrated the presence of bioactive compounds inhibited TNFa, HER2, and MMP9 as the target protein. The molecular dynamic result was confirmed using molecular dynamic and it shows that $\beta-$ asarone interaction was stable against MMP9 and TNF protein showed by the low RMSD value. The study found the investigated bioactive compounds of Piper crocatum have the activity of anti-cancer via the inhibition of TNFa and MMP9 protein. However, further research still needs to be done to confirm the prediction results of this In Silico study.

Keywords: anticancer, In Silico, molecular docking, Piper crocatum.

\section{INTRODUCTION}

Cancer is one of the leading causes of death and a significant barrier to increasing life expectancy all over the world. Cancer is a disease that arises from the abnormal growth of body cells which turn into cancer cells. The urgency of finding effective cancer treatment has become one of the oncology researchers' primary focuses. Commonly, the development of an anticancer drug is conducted through in vitro and in vivo studies, which is time and cost-consuming. In Silico study is reported to be the alternative to screening herbal-based anticancer agents and cancer drug discovery [1]. The screening of anticancer from several herbal plants through the In Silico method is effective due to advancements, such as web servers that provide prediction tools and databases. The web servers that often to be used in anticancer in silico study are STITCH (http://stitch.embl.de/), Prediction of Activity Spectra for Substances (PASS) online (http://way2drug.com/PassOnline/), and SwissADME (http://www.swissadme.ch/) [2]. In addition, in silico software-based analyses such as molecular docking and molecular dynamics can

\footnotetext{
${ }^{*}$ Correspondence address:

Ahmed Hasan Abkar

E-mail : hamadah118850@gmail.com

Address : Dept. Biology, University of Brawijaya, Veteran Malang, 65145.
}

be used to determine the interaction of bioactive compounds against the cancer-related protein.

Red Betel Leaf (Piper crocatum Ruiz \& Pav) is a medicinal plant that is often used to treat various diseases such as cancer, cough, asthma, nasal inflammation, and sore throat [3]. Empirically, the formulation of Piper crocatum leaf extract with other medicinal plants demonstrates the eradication of various diseases, such as inflammation, bleeding, breast cancer, uterine cancer, leukemia, and liver swelling [4].

The chemical content of Piper Crocatum leaf plants based on chromatography analysis are flavonoids, polyphenols, alkaloids, tannins, and essential oils [5]. The flavonoid content is included in the class of polyphenols that are distributed in parts of the plant body and have the activities to inhibit tumor cell growth, migration, metastasis, and endothelial activation [6]. Piper Crocatum also has cytotoxic activity against 4T1 metastasis of breast cancer cells at IC50 $120 \mu \mathrm{g} / \mathrm{mL}$ and inhibits migration activity at a concentration of $30 \mu \mathrm{g} / \mathrm{mL}(1 / 4$ of IC50) [6]. Piper crocatum also inhibited the proliferation of T47D and HeLa, and cytotoxic against colon cancer cells [6].

Several proteins play a significant role in the progression and development of cancer, such as HER2 (human epidermal growth receptor 2), MMP9 (matrix metalloproteinase-9), and TNF $\alpha$ (tumor necrosis factor $\alpha$ ). The activity of HER2 leads to the 
initiation of signaling pathways and possession of cell proliferation and tumorigenesis [7]. The MMP9 protein is a well-known protein found to be associated with the pathogenesis of tumors, such as metastasis and angiogenesis [8]. Besides, TNF $\alpha$ is a pro-inflammatory cytokine that is associated with carcinogenesis inflammation [9]. Based on the role of some proteins mentioned above, the inhibition of those proteins is the potential to be the target in cancer therapy.

Previous studies on $\beta$-asarone, methyl piperonylketone, and coumaric acid interaction against HER2, MMP9, and TNF $\alpha$ proteins in cancer remain unclear. To address this unclarity, the study aims to determine the potential of $\beta$ asarone, methyl piperonylketone, and coumaric acid from Piper crocatum as an anticancer agent via the blockade of HER2, MMP9, and TNF $\alpha$ proteins through in silico study.

\section{METHODS}

The study was a qualitative study that used an observational descriptive research design using exploratory research as secondary data since in vitro and in vivo studies cost and time constraints. Thus, this study was a preliminary study and screening method for the prediction of anticancer agents from bioactive compounds of herbal plants.

The anticancer effects of Piper crocatum bioactive compounds such as $\beta$-asarone, methyl piperonylketone, and coumaric acid were conducted through In Silico study. The analysis of this study included biological activity, cell line cytotoxicity activity, SwissADME, STITCH, molecular docking, and molecular dynamics simulation.

\section{Data Collection}

The canonical smile of the compounds used in the analysis of biological activity, cell line cytotoxicity activity, and SwissADME, and the 3D structure of investigated compounds were retrieved from PubChem (https://pubchem.ncbi. nlm.nih.gov/). The the canonical smile and compound ID of PubChem retrieval were $\beta$ asarone $\quad \mathrm{CC}=\mathrm{CC} 1=\mathrm{CC}(=\mathrm{C}(\mathrm{C}=\mathrm{C} 1 \mathrm{OC}) \mathrm{OC}) \mathrm{OC}$ (CID_5281758), p-coumaric acid $\mathrm{C} 1=\mathrm{CC}(=\mathrm{CC}=\mathrm{C} 1 \mathrm{C}=\mathrm{CC}(=0) 0) \mathrm{O}\left(\mathrm{CID} \_637542\right)$, and methyl piperonylketone $\mathrm{CC}(=\mathrm{O}) \mathrm{CC} 1=\mathrm{CC} 2=\mathrm{C}(\mathrm{C}=\mathrm{C} 1) \mathrm{OCO} 2$ (CID_78407). The protein 3D structure of TNF $\alpha$ and TNF $\alpha$ receptors (TNFR2), HER2, and MMP9 were obtained from protein data bank PDB (https://www.rcsb.org/) with protein ID of PDB retrieval were MMP9 (PDB ID 1gkc), HER2 (PDB ID 1n8z), and TNF $\alpha$ and TNFR2 (PDB ID 3alq).

\section{Data Analysis}

The analysis of the biological activity of investigated bioactive compounds was performed by the PASS web server (http://way2drug.com/ PassOnline/index.php), and the canonical smile of each bioactive compound was inserted. The parameters $\mathrm{Pa}$ as "being active" and $\mathrm{Pi}$ as "being inactive" were obtained in this study. The higher the $\mathrm{Pa}$ value, the bigger potential of the biological activity of the compound [1]. The study used the cutoff value of $\mathrm{Pa}$ value in 0.7. Additionally, the cytotoxic activity was also done in PASS through different weblinks (http://www.way2drug.com/cellline/). It was used to predict the cytotoxic activity of compounds in cancer and normal cell lines. The highest potential of anticancer activity against a specific protein (represented by the highest Pa value) based on PASS analysis was then used for further analysis.

The pharmacological properties of investigated bioactive compounds were analyzed using the SwissADME web server (http://www.swissadme.ch) by inserting the canonical smile of each compound. The STITCH analysis was done through a web server (http://stitch.embl.de/) by inserting the name of investigated bioactive compounds.

The molecular docking analysis was done to determine the interaction of investigated bioactive compounds against the TNF $\alpha$, TNFR2, HER2, and MMP9 proteins. Molecular docking was performed by HEX software and visualized using Discovery Studio ver 19.0. The lowest binding affinity of protein-ligand interaction based on molecular docking analysis results was then analyzed further for a molecular dynamics simulation using YASARA software [10].

\section{RESULT AND DISCUSSION}

\section{Biological Activity Analysis using PASS Online}

Based on PASS analysis, coumaric acid showed higher probabilities for the antimutagenic (0.886/0.002), TNF expression inhibitor (0.737/0.005), and MMP9 expression inhibitor $(0.818 / 0.003)$. Congruently, methyl piperonylketone 
also showed biological activity as an MMP9 expression inhibitor (0.745/0.004). Additionally, the $\beta$-asarone showed higher probabilities for the TNF expression inhibitor $(0.739 / 0.005)$ and MMP9 expression inhibitor $(0.809 / 0.003)$. The prediction of the bioactive compound's biological activity through PASS analysis was shown in Table 1. In line with these results, the flavonoid activity contained in Piper crocatum was reported to have the activity of inhibiting cancer cell migration via suppressing MMP-9 expression and FAK phosphorylation [8].

Table 1. Biological activity of coumaric acid, beta asaron, and Methyl piperonyl ketone.

\begin{tabular}{|c|c|c|c|}
\hline $\begin{array}{l}\text { Bioactive } \\
\text { compounds }\end{array}$ & $\begin{array}{c}\text { Anticancer } \\
\text { Activity }\end{array}$ & $P a$ & $P i$ \\
\hline \multirow{3}{*}{ 4-coumaric acid } & Anti-mutagenic & 0.886 & 0.002 \\
\hline & $\begin{array}{l}\text { TNF expression } \\
\text { inhibitor }\end{array}$ & 0.737 & 0.005 \\
\hline & $\begin{array}{l}\text { MMP9 expression } \\
\text { inhibitor }\end{array}$ & 0.818 & 0.003 \\
\hline $\begin{array}{l}\text { Methyl } \\
\text { Piperonylketone }\end{array}$ & $\begin{array}{l}\text { MMP9 expression } \\
\text { inhibitor }\end{array}$ & 0.745 & 0.004 \\
\hline \multirow{2}{*}{$\beta$-Asarone } & $\begin{array}{l}\text { TNF expression } \\
\text { inhibitor }\end{array}$ & 0.739 & 0.005 \\
\hline & $\begin{array}{l}\text { MMP9 expression } \\
\text { inhibitor }\end{array}$ & 0.809 & 0.003 \\
\hline
\end{tabular}

Cell Line Cytotoxicity Prediction through CLCPred Analysis

A CLC-Pred is a well-known tool in cheminformatics and medicinal chemistry, was used to predict the toxicity of compounds against the cell line type and tissue to the respective tumor type. The maximum number of different cell line predictions were collected and tabulated with the respective cell line and type of cell.

Table 2. CLC-Pred analysis of cell line cytotoxicity prediction

\begin{tabular}{ccccc}
\hline $\begin{array}{c}\text { Bioactive } \\
\text { compound }\end{array}$ & $\begin{array}{c}\text { Cell } \\
\text { line }\end{array}$ & Tumor type & Pa & Pi \\
\hline $\begin{array}{c}\text { 4-Coumaric } \\
\text { acid }\end{array}$ & $\begin{array}{c}\text { IGROV- } \\
1\end{array}$ & Adenocarcinoma & 0.628 & 0.009 \\
\hline $\begin{array}{c}\text { Methyl } \\
\text { Piperonyl } \\
\text { Ketone }\end{array}$ & Hs 683 & Glioma & 0.659 & 0.015 \\
\hline $\begin{array}{c}\beta- \\
\text { Asarone }\end{array}$ & K562 & Leukemia & 0.484 & 0.029 \\
\hline
\end{tabular}

The compound of coumaric acid and methyl piperonylketone showed significant cytotoxicity against adenocarcinoma ( $\mathrm{Pa}$ value $=0.628)$ and Glioma (Pa value $=0.659)$. Likewise, $\beta$-asarone cytotoxic against leukemia cells showed a Pa value of 0.484 (Table 2).

\section{Investigated Bioactive Compound-Protein Interaction Analysis Using STITCH}

The STITCH analysis results showed only $p$ coumaric acid having compound-protein interaction. However, methyl piperonylketone and $\beta$-asarone showed no interaction with any protein. Based on the data, there were several proteins involved in the interaction against the p-coumaric acid (Figure 1). The network showed several biological processes in the body that can be summarized and confirmed using the KEGG pathway (Table 3).

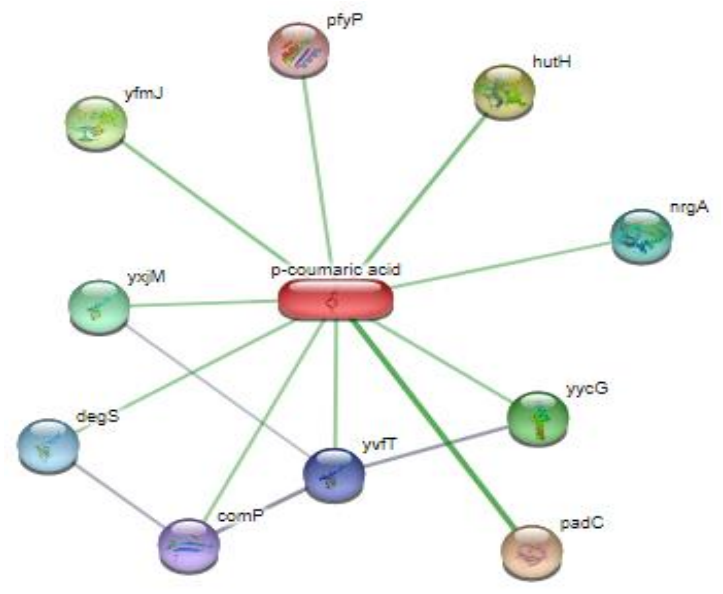

Figure 1. STITCH analysis results of p-coumaric acid-protein interaction

The gene set was involved in several pathways such as peptidyl-histidine phosphorylation, signal transduction by protein phosphorylation, the phosphorelay signal transduction system, single organism signaling, response to stimulus, cell communication, cellular response to stimulus, aromatic compound catabolic process, and twocomponent systems. One of the pathways associated with cancer was histidine phosphorylation which was reported to be involved in the development of hepatocellular carcinoma [11].

Histidine phosphorylation was also linked to the migration and differentiation of neuroblastoma cells and tumors through the expression of NME1 and NME2 [12]. In addition, protein phosphorylation induced signal transduction that affected several cancer-related processes, including cell apoptosis, proliferation, angiogenesis, metastasis, and several cancer therapies through the phosphorylation of key proteins (p38, MAPK, ERK, PI3K, STAT3, and p53)[13].

Table 3. Protein involvement based on the KEGG pathway 
(Abkar, et al.)

\begin{tabular}{clll}
\hline Pathway ID & \multicolumn{1}{c}{ Pathway Description } & \multicolumn{1}{c}{$\begin{array}{c}\text { Galse } \\
\text { discovery } \\
\text { rate }\end{array}$} & $\begin{array}{c}1.18 \mathrm{e}-07 \\
\end{array}$ \\
\hline 0018106 & peptidyl-histidine phosphorylation & DEGS, COMP, YVFT, YYCG, YXJM, PFYP & $1.18 \mathrm{e}-07$ \\
0023014 & signal transduction by protein phosphorylation & DEGS, COMP, YVFT, YYCG, YXJM, PFYP & $4.1 \mathrm{e}-06$ \\
0000160 & phosphorelay signal transduction system & DEGS, COMP, YVFT, YYCG, YXJM, PFYP & $7.63 \mathrm{e}-06$ \\
0044700 & single organism signaling & DEGS, COMP, YVFT, YYCG, YXJM, PFYP & $2.09 \mathrm{e}-05$ \\
0050896 & response to stimulus & DEGS, COMP, YVFT, YYCG, YXJM, PFYP, PADC, YFMJ & 0.000103 \\
0007154 & cell communication & DEGS, COMP, YVFT, YYCG, YXJM, PFYP & 0.000519 \\
0051716 & cellular response to stimulus & DEGS, COMP, YVFT, YYCG, YXJM, PFYP & 0.022 \\
0019439 & the aromatic compound catabolic process & PADC, YFMJ, HUTH & 0.0141 \\
02020 & two-component system & DEGS, COMP, YVFT, YYCG & \\
\hline
\end{tabular}

\section{Pharmacological Property Analysis}

The pharmacological property analysis was done using the SwissADME server to determine the ability of adsorbs, distribution, metabolism, and excretion of compounds. In Table 4, the radar image showed by the pink zone was the optimum zone. The optimum characteristics of the compound for oral consumption were as follows: having a molecular weight of 150-500 g.mol ${ }^{-1}$, a polarity with the TPSA being between 20-130Å2, a solubility with a log $S$ not more than 6 , flexibility with no more than nine rotatable bonds, and lipophilicity XLOGP3 between -0.7 and +5.0 [14]. Based on the data in Table 4, almost all compounds have good pharmacological properties, except the fairly low saturation of coumaric acid.

Table 4. Pharmacological property of SwissADME Analysis

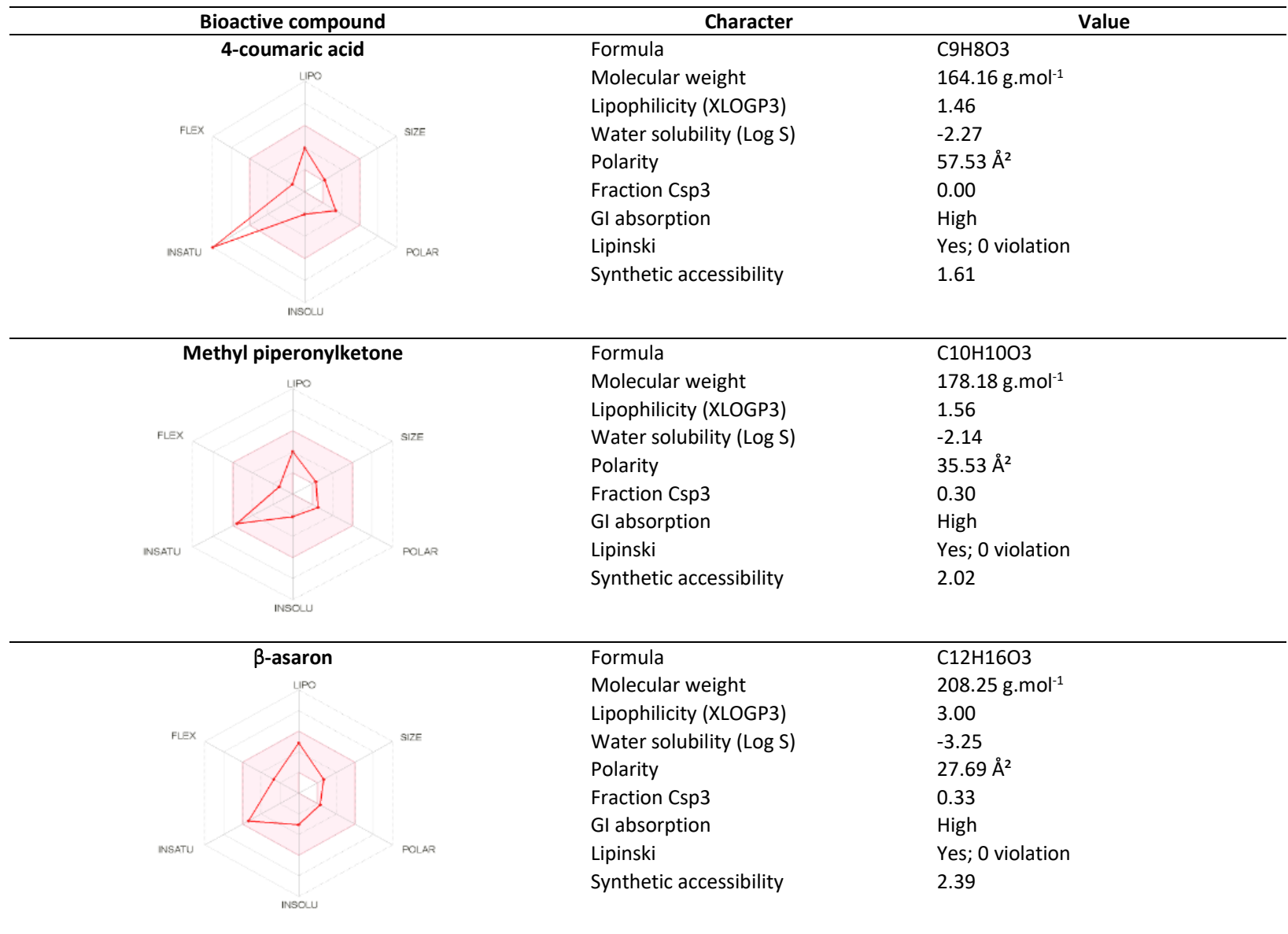

Molecular Docking

J.Exp. Life Sci. Vol. 11 No. 3, 2021

ISSN. 2087-2852 
Based on the molecular docking results, the interaction of investigated bioactive compounds against HER2 protein is shown in Table 5 and Figure 2. The interaction of complex $\beta$-asarone and HER2 protein was the strongest compared to other complexes shown by the lowest binding energy $\left(-196.7 \mathrm{cal}^{\mathrm{mol}}{ }^{-1}\right)$ followed by coumaric acid $\left(-180.9 \mathrm{cal}^{\mathrm{mol}}{ }^{-1}\right)$ and methyl piperonylketone $\left(-172.2 \quad \mathrm{cal}^{\mathrm{mol}}{ }^{-1}\right)$. The interaction of $\beta$-asarone and HER2 protein demonstrated the higher number of hydrogen bonds via GLU873, GLN902, and GLU964. $\beta$-asarone also has the lowest binding energy in the interaction against the MMP9 protein. The binding energy of $\beta$-asarone against the MMP9 protein was $-216.09 \mathrm{cal}^{\mathrm{mol}}{ }^{-1}$ in the form of 3 hydrogen bonds. Additionally, the binding energy of methylpiperonyl ketone and coumaric acid against MMP9 protein interaction was -203.41 and -220.9 cal.mol ${ }^{-1}$, respectively (Table 6 , Fig. 3). The complex of $\beta$-asarone and MMP9 protein also showed higher hydrogen bonds compared to the other ligandprotein complexes.

Table 5. The interaction of complex ligand-HER2 proteins

\begin{tabular}{|c|c|c|c|}
\hline Complex Ligand-Protein & Interaction & Category & Binding energy (cal.mol ${ }^{-1}$ ) \\
\hline \multirow{4}{*}{$\beta$-Asarone-HER2 } & :LIG1:H - B:GLU837:OE1 & Hydrogen Bond & \multirow{4}{*}{-196.7} \\
\hline & :LIG1:H - B:GLN902:OE1 & Hydrogen Bond & \\
\hline & :LIG1:H - B:GLU964:OE2 & Hydrogen Bond & \\
\hline & :LIG1:H - B:GLU964:OE2 & Hydrogen Bond & \\
\hline \multirow{3}{*}{ Methylpiperonyl ketone-HER2 } & :LIG1:H - A:VAL754:O & Hydrogen Bond & \multirow{3}{*}{-172.2} \\
\hline & A:THR793:CG2 -:LIG1 & Hydrophobic & \\
\hline & :LIG1 - A:VAL754 & Hydrophobic & \\
\hline \multirow{4}{*}{ p-Coumaric acid-HER2 } & :UNK1:H19 - A:SER728:O & Hydrogen Bond & \multirow{4}{*}{-180.9} \\
\hline & A:SER728:CB -:UNK1:O11 & Hydrogen Bond & \\
\hline & A:ARG849:CD - :UNK1:010 & Hydrogen Bond & \\
\hline & :UNK1 - A:ALA730 & Hydrophobic & \\
\hline
\end{tabular}

\section{B-Asarone-HER2}

a

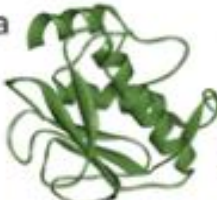

Methylpiperonyl ketone-HER2

a

a

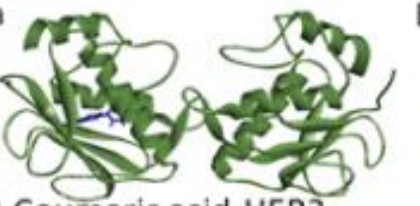

P-Coumaric acid-HER2

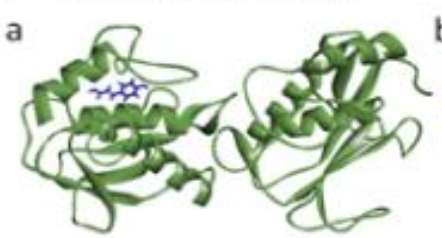

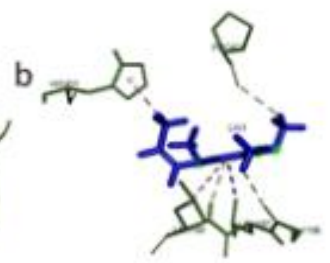

\section{R2}
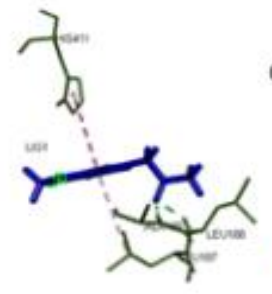


c

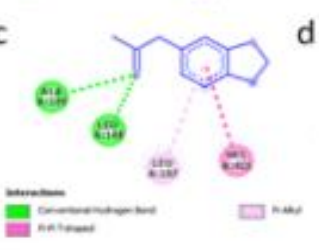

d
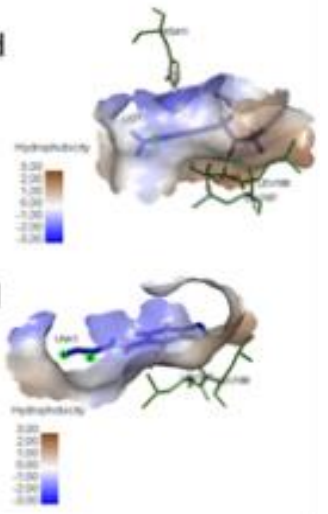

Figure 2. Interaction between $\beta$-Asarone, Methyl piperonylketone, and P-Coumaric acid on HER2 protein, a. overview of the ligandprotein complex, b. the active site of ligand-protein complex interactions, c. the 2D structure of the ligand-protein complex, d. hydrophobicity of the ligand-protein bond complex. The green color is the HER2 protein, the blue color is a compound.

Table 6. The interaction of complex ligand-MMP9 proteins 
In Silico Study to Predict the Potential Anticancer Agents

(Abkar, et al.)

\begin{tabular}{|c|c|c|c|}
\hline Complex Ligand-Protein & Interaction & Category & Binding energy (cal.mol ${ }^{-1}$ ) \\
\hline \multirow{6}{*}{$\beta$-Asarone-MMP9 } & :LIG1:H - B:GLY186:O & Hydrogen Bond & \multirow{6}{*}{-216.09} \\
\hline & :LIG1:H - B:PRO421:O & Hydrogen Bond & \\
\hline & B:LEU188:HN -:LIG1 & Hydrogen Bond & \\
\hline & B:LEU187:CD1 - :LIG1 & Hydrophobic & \\
\hline & B:HIS401 - :LIG1:C & Hydrophobic & \\
\hline & :LIG1 - B:LEU188 & Hydrophobic & \\
\hline \multirow{4}{*}{ Methylpiperonyl ketone-MMPg } & A:LEU188:HN -:LIG1:O & Hydrogen Bond & \multirow{4}{*}{-203.41} \\
\hline & A:ALA189:HN - :LIG1:O & Hydrogen Bond & \\
\hline & A:HIS411 - :LIG1 & Hydrophobic & \\
\hline & :LIG1 - A:LEU187 & Hydrophobic & \\
\hline \multirow{2}{*}{ p-Coumaric acid-MMPg } & A:LEU187:CD1 - :UNK1 & Hydrophobic & \multirow{2}{*}{-220.9} \\
\hline & A:LEU188:HN - :UNK1:H20 & Unfavorable & \\
\hline
\end{tabular}

B-Asarone-MMPg

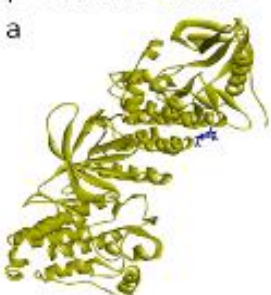

Methylpiperonyl ketone-MMP9

a

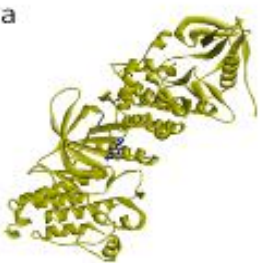

P-Coumaric acid-MMPg

a

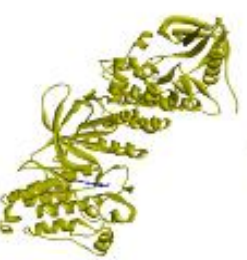

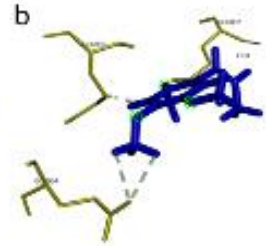

b

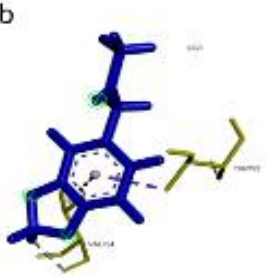

b

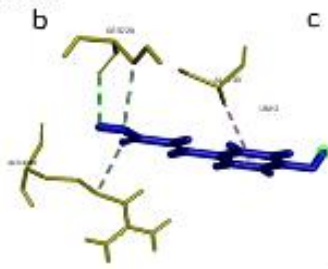

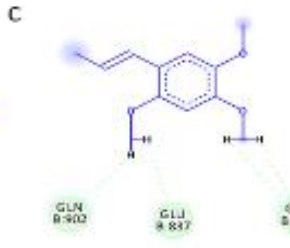

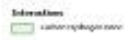
Unfavorable

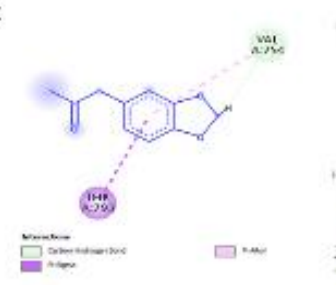

d

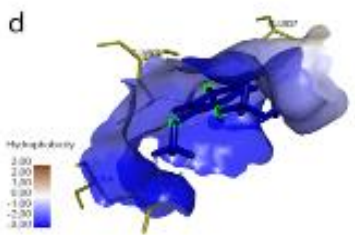

d
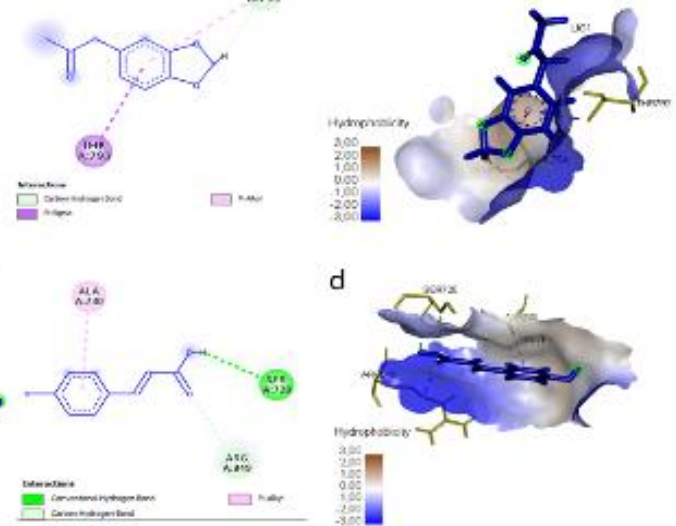

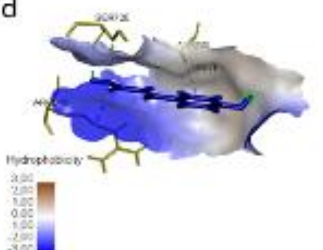

Figure 3. Interaction between B-Asarone, Methylpiperonyl ketone, and P-Coumaric acid on the matrix metalloproteinase-9 protein, a. overview of the ligand-protein complex, b. the active site of ligand-protein complex interactions, c. the 2D structure of the ligand-protein complex, $\mathbf{d}$. hydrophobicity of the ligand-protein bond complex. The yellow color is the MMP9 protein, the blue color is a compound.

Table 7. The interaction of complex ligand-TNFa

\begin{tabular}{|c|c|c|c|}
\hline Complex Ligand-Protein & Interaction & Category & Binding energy $\left(\mathrm{cal}^{\mathrm{mol}} \mathrm{m}^{-1}\right)$ \\
\hline \multirow{3}{*}{$\beta$-Asarone-MMP9 } & B:GLN102:HN - :LIG1:O & Hydrogen Bond & \multirow{3}{*}{-192} \\
\hline & :LIG1:H - A:GLU116:OE2 & Hydrogen Bond & \\
\hline & B:PRO100:C,O;CYS101:N - :LIG1 & Hydrophobic & \\
\hline \multirow{3}{*}{ Methylpiperonyl ketone-MMP9 } & :LIG1:H - A:PRO100:O & Hydrogen Bond & \multirow{3}{*}{-178.2} \\
\hline & :LIG1:H - B:GLN102:OE1 & Hydrogen Bond & \\
\hline & B:ARG98:NH2 - :LIG1 & Hydrogen Bond & \\
\hline \multirow{2}{*}{ p-Coumaric acid-MMP9 } & :UNK1:H20 - F:PRO100:O & Hydrogen Bond & \multirow{2}{*}{-175.7} \\
\hline & F:ARG98:NH2 - :UNK1 & Electrostatic & \\
\hline
\end{tabular}



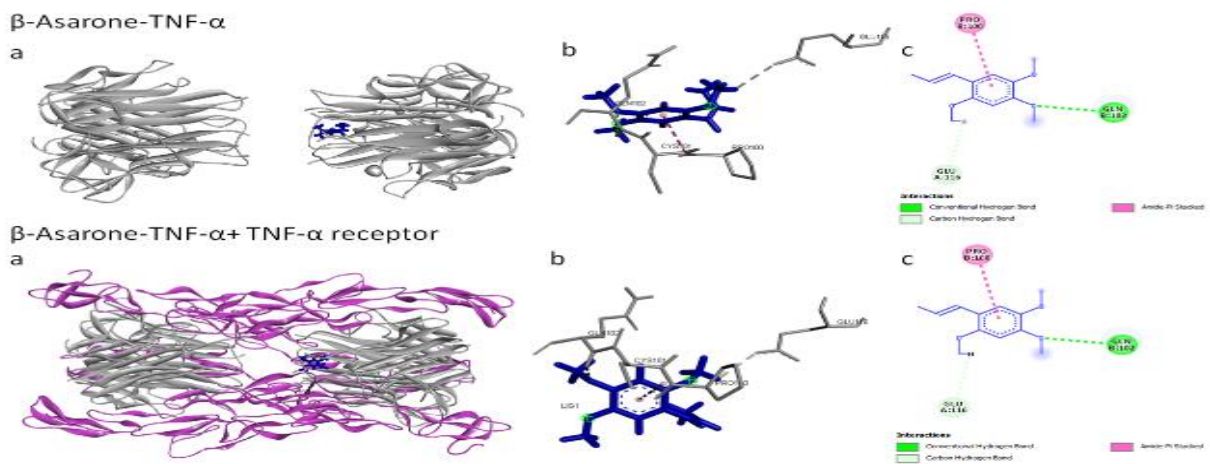

c
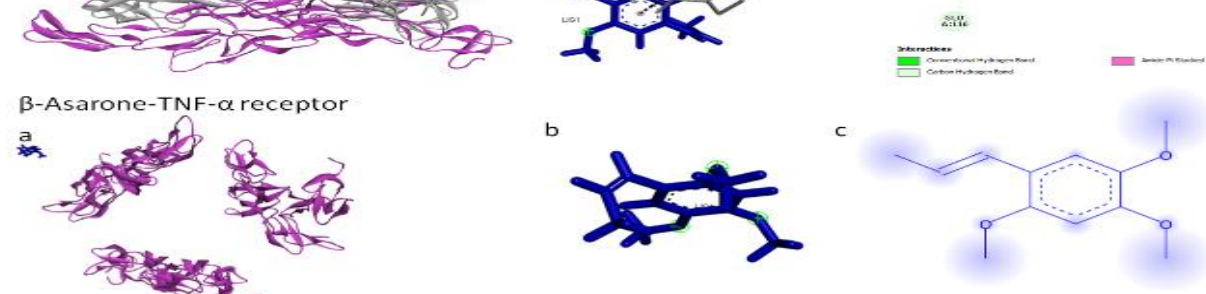

$\beta$-Asarone-TNF-dreceptor + TNF- $\alpha$

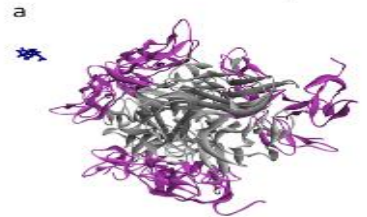

b
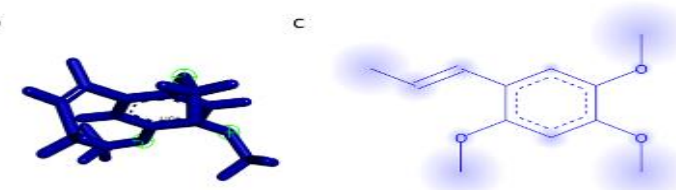

Figure 4. Interaction between B-Asarone against TNF- $\alpha$ inhibition and TNF- $\alpha$ receptors, a. overview of the ligand-protein complex, b. the active site of ligand-protein complex interactions, $c$. the $2 \mathrm{D}$ structure of the ligand-protein complex.

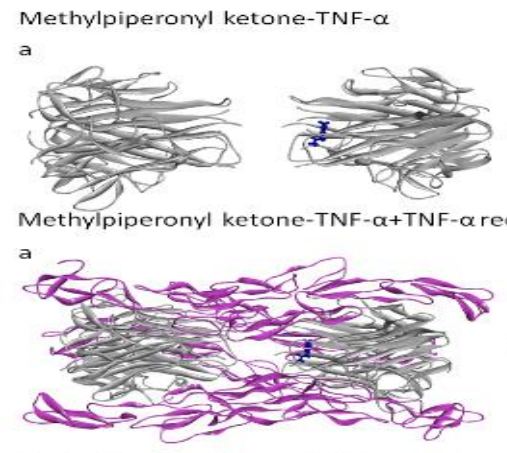

Methylpiperonyl ketone-TNF- $\alpha$ receptor

a

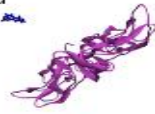

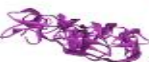

Methylpiperonyl ketone-TNF- $\alpha$ receptor +TNF- $\alpha$ a

$\rightarrow$

b b $\quad$ c

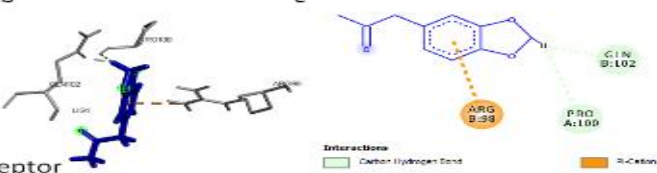

b<smiles>[TeH]</smiles>
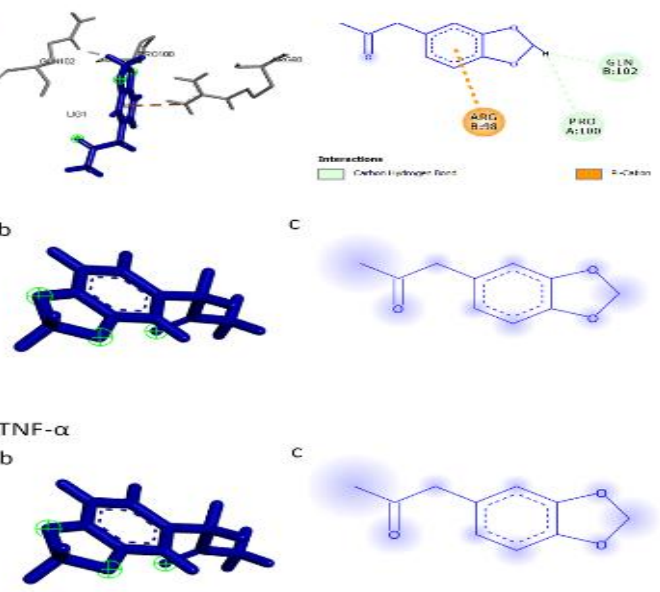

Figure 5. Interaction between Methyl piperonylketone against TNF- $\alpha$ inhibition and TNF- $\alpha$ receptors, a. overview of the ligandprotein complex, b. the active site of ligand-protein complex interactions, c. the 2D structure of the ligand-protein complex. 


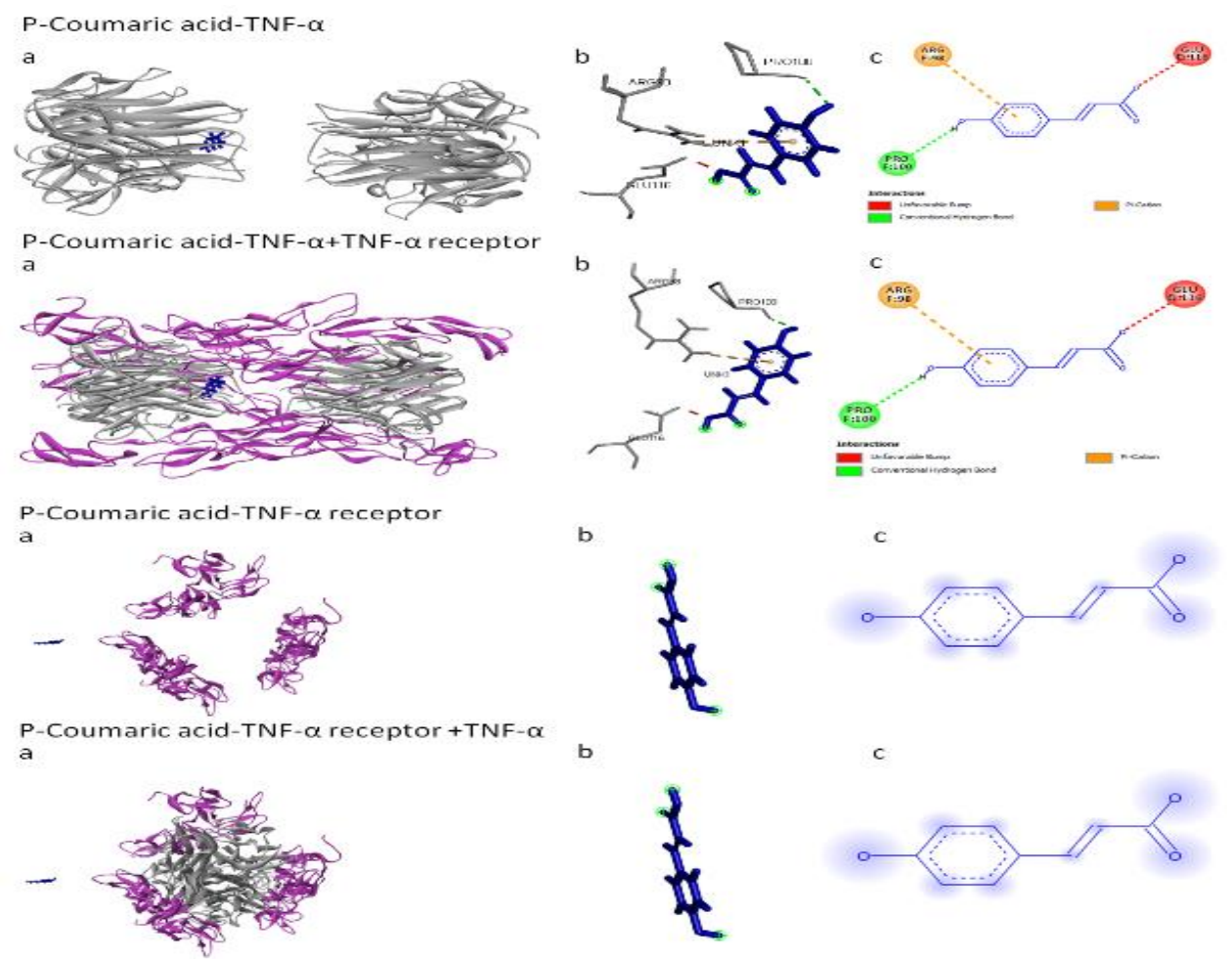

Figure 6. Interaction between P-Coumaric acid against TNF- $\alpha$ inhibition and TNF- $\alpha$ receptors, a. overview of the ligand-protein complex, b. the active site of ligand-protein complex interactions, c. the 2D structure of the ligand-protein complex.

Molecular docking analysis showed that $\beta$ Asarone can bind to TNF- $\alpha$ at the same residue as TNF- $\alpha$ binds to the TNF- $\alpha$ receptor (Fig. 4). Key residues involved in the interaction of TNF- $\alpha$ and TNF- $\alpha$ receptors include GLN100, GLU116, and PRO100. This study found $\beta$-asarone were also able to bind GLN100, GLU116, and PRO100 from TNF- $\alpha$ stabilized by hydrogen bonds and hydrophobic bonds with a binding energy of $-192 \mathrm{kcal}^{\mathrm{mol}}{ }^{-1}$ (Table 7) and assumed to have the ability to interfere with the interaction of TNF- $\alpha$ and the receptor. Besides, methyl piperonylketone compound was also predicted to inhibit TNF- $\alpha$ binding to the TNF- $\alpha$ receptor via the involvement of key residues PRO100, GLN102, ARG98 residues of TNF- $\alpha$ (Fig. 5, Table 7).

The interaction of TNF- $\alpha$ and methyl piperonylketone was formed by hydrogen and electrostatic forces with a binding energy of -178.2 $\mathrm{cal}^{\mathrm{mol}}{ }^{-1}$. The results of the molecular docking showed that this compound was unable to interact with the TNF- $\alpha$ receptor. The compound of $p$ coumaric acid can inhibit TNF- $\alpha$ binding to the TNF$\alpha$ receptor shown by the binding of coumaric acid to the PRO100 and ARG98 key residues of TNF- $\alpha$
(Fig. 6, Table 7). The interaction of TNF- $\alpha$ and coumaric acid was formed by hydrogen bonds and electrostatic forces with a binding energy of -175.7 cal. $\mathrm{mol}^{-1}$.

The hydrogen bonds formed between ligands and proteins are crucial for the interactions because hydrogen bonds hugely contribute to the structure of the bonds, which can increase the stability of the interaction [8]. The molecular docking analysis showed the strongest and most stable interaction among the three bioactive compounds was $\beta$-asarone against each protein. This interaction was also predicted to potentially inhibit the protein target, including HER2, MMP9, and TNFa, via the involvement of key amino acid residues. Furthermore, the interaction of $\beta$-asarone against each protein was confirmed and further analyzed using a molecular dynamics simulation.

Based on the molecular docking analysis and supporting data from the previous studies, the possible mechanisms of the action from the bioactive compound that may occur were presented in Figure 7. Under normal conditions, cells can grow, move and invade cells through two pathways, namely the TNFa/TNFR2 and HER2 
pathways. In the TNFa/TNFR2 pathway, proinflammatory cytokines such as TNFa bind to TNFR2 and indirectly activate NFkB. Likewise, the active HER2 will induce AKT phosphorylation and NFkB activation. The active NFkB will stimulate the expression of the NTN1 gene that encodes the NETRIN1 protein. The NETRIN1 protein causes invasive cells. On the other hand, the HER2 protein also activates FAK and Src, both of which activate the JNK protein for phosphorylation and induce MMP9 activity for cell motility and development. The presence of Piper Crocatum bioactive compounds inhibits TNFa, HER2, and MMP9, causing motility and invasiveness, preventing cell development from occurring.

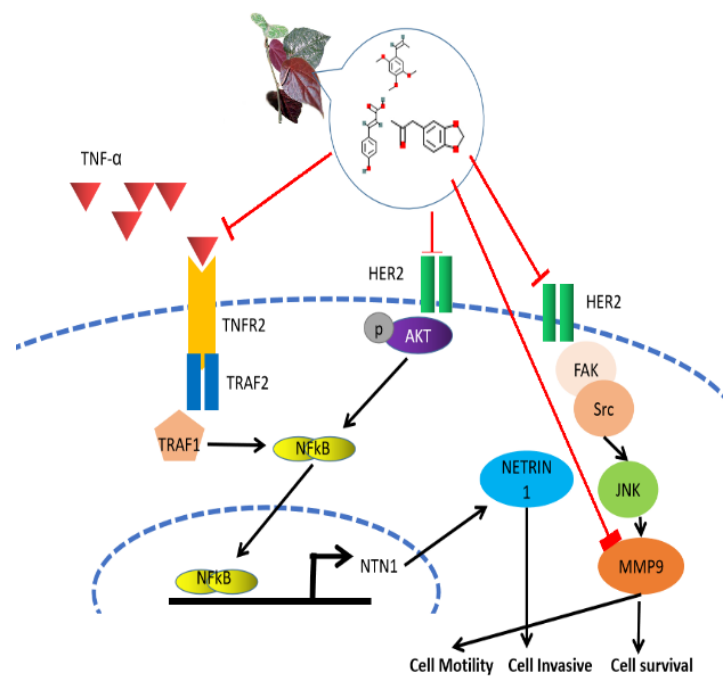

Figure 7. Mechanism of Piper crocatum Ruiz \& Pav bioactive compounds as anticancer through inhibition of the TNFa/TNFR2, HER2, and MMP9 pathways. The mechanism pathway is based on Wang et al [15] and Rossi et al [16].

\section{Molecular Dynamics}

The molecular dynamic study was done to analyze the complex of $\beta$-asarone, as the most potential of bioactive compounds in inhibiting each target protein that showed by the lowest binding affinity in molecular docking results. The Root Mean Square Deviation (RMSD) value of complex protein-ligand is shown in Figure 8.

RMSD was the average displacement of atoms during a simulation towards their corresponding structure. The RMSD value was used to determine whether the structure was stable over a certain period from the simulation of changes [17]. RMSD was a calculation of the average distance between the backbone atoms of a protein superimpose [18]. A good RMSD value was $3 \AA$ range or below. However, when the RMSD value reaches $3 \AA$ or exceeds $3 \AA$, it indicates that the protein structure has changed [17].

\section{RMSD Complex protein-ligand}

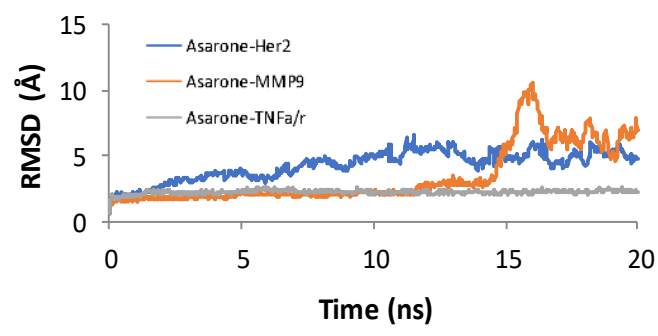

Figure 8. The simulation results of molecular dynamics of RMSD Complex protein-ligand

Based on the molecular dynamics data results, there were three charts on the graph, such as green ( $\beta$-asarone and TNF), orange ( $\beta$-asarone and MMP9), and blue ( $\beta$-asarone and HER2) (Fig. 8). The study found that the most stable interaction of complex protein-ligand was $\beta$-asarone and TNF, which was shown by a flat graph with an RMSD value of under $4 \AA$ [19] compared to a higher RMSD value and fluctuating chart of $\beta$-asarone against MMP9 and HER2. $\beta$-asarone and MMP9 were initially formed stable molecules until the $15 \mathrm{~ns}$. It was assumed there was a change in the position of the ligand-protein complex. A change in position can be caused by the release of the ligand from the protein or by its movement.

To support the result of complex protein-ligand RMSD, the molecular dynamics analysis also showed the RMSD ligand movement, as shown in Figure 9. RMSD ligand movement was used to see how the ligand moves when it interacted with proteins. The study found that the ligand movement in the complex of $\beta$-asarone with TNF and MMP9 protein were stable compared to the HER2 protein. The instability of $\beta$-asarone against HER2 protein showed by a high RMSD ligand value that indicates instability of the ligand in the structure so that the ligand will continue to move [17]. RMSD ligands demonstrate the translational and rotational movement of ligands and characterize the binding or dissociation process [18]. Based on this information, it was concluded 
that $\beta$-asarone has an unstable interaction (or even can be detached from its interaction) with the HER2 protein. However, the ligand conformation of $\beta$-asarone appeared stable when interacting with MMP9, HER2, and TNFa/ $r$ showed by all the RMSD ligand conformation value were 1-2 $\AA$.

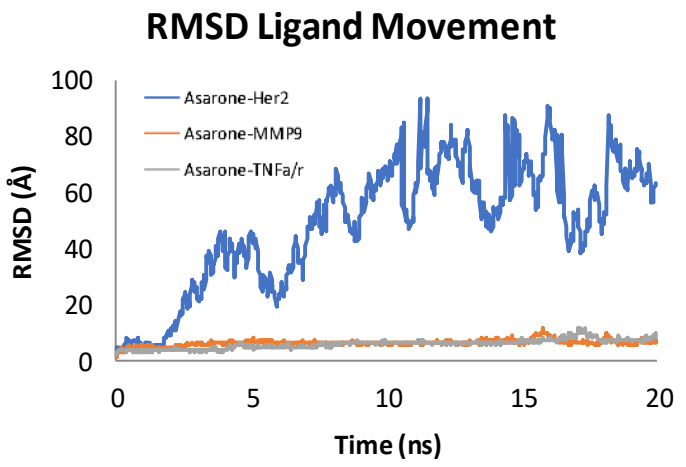

Figure 9. Results of molecular dynamics simulation results of RMSD Ligand movement

\section{RMSD Ligand conformation}

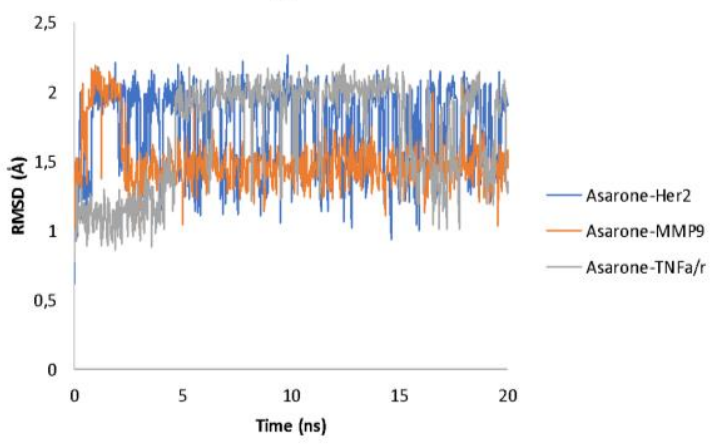

Figure 10. Results of molecular dynamics simulation results of RMSD Ligand

The stability of ligand-protein is demonstrated by the distance between the ligand-protein. This study found that $\beta$-asarone interaction against MMP9 and TNF protein was stable, at least until 14ns for MMP9 (Fig. 8). These results were confirmed by the RMSD value of ligand movement that showed the stable movement of $\beta$-asarone against MMP9 and TNF interaction (Fig. 9). In addition, the ligand conformation against all target proteins were demonstrating a 1-2 A RMSD value showing a stable conformation of the ligand.

We demonstrate that the best interaction of $\beta$ asarone based on molecular dynamic analysis against target protein were the complex of $\beta$ asarone with MMP9 and TNFa, showed by the stable ligand-protein complex, ligand movement, and ligand conformation. The interaction of $\beta$ asarone and HER2 may also potential but these complex remain unstable in the condition of living systems as a study of molecular dynamic.

\section{CONCLUSION}

The results showed the biological activities of coumaric acid, methyl piperonylketone, and $\beta$ asarone were anti-mutagenic, TNF expression inhibitor, and MMP 9 expression inhibitor. The study also found the investigated bioactive compounds were cytotoxic on various tumor cells, including glioma, adenocarcinoma, and leukemia. Based on swissADME results, almost all compounds have optimum pharmacological properties, such as molecular weight, polarity, solubility, flexibility, and lipophilicity, except for coumaric acid, which has a fairly low saturation. Based on the docking analysis result, the investigated bioactive compounds inhibit TNFa, HER2, and MMP9 causing motility, invasiveness, and tumor cell development to not occur.

Based on these findings, it can be concluded that the methyl piperonylketone, $\beta$-asarone, and coumaric acid in Piper crocatum have the potential to be anticancer. The molecular dynamics of $\beta$ asarone and the protein target interaction showed that the TNF $a / r$ protein was stable when interacting with the $\beta$-asarone ligand. The RMSD ligand movement showed that $\beta$-asarone ligand conformation appeared stable when interacting with MMP9, HER-2, and TNFa/r because the RMSD value was seen from the minimum fluctuation of the RMSD ligand conformation value and did not exceed $3 \AA$. In addition, this in silico study still needs further research to confirm this finding using in vitro or in vivo study to the respective cancer type.

\section{REFERENCES}

[1] Lagunin, A.A., V.I. Dubovskaja, A.V. Rudik, P.V. Pogodin, D.S. Druzhilovskiy, T.A. Gloriozova, D.A. Filimonov, N.G. Sastry, V.V. Poroikov. 2018. CLC-Pred: a freely available web service for in silico prediction of human cell line cytotoxicity for drug-like compounds. PloS one. 13(1). p.e0191838.

[2] Nafisah, W., H.N. Pinanti, Y.I. Christina, M. Rifa'i, M.S. Djati. 2021. Computational biological activity and pharmacological properties analysis for anticancer Cyperus 
rotundus bioactive compounds. AIP Conference Proceedings 2353(1). 030118. AIP Publishing LLC.

[3] Haryadi, R.B. 2010. Daya antibakteri ekstrak daun sirih (Piper betle) dan daun sirih merah (Piper crocatum) terhadap pertumbuhan bakteri Staphylococcus aureus secara In Vitro sebagai materi praktikum mikrobiologi. Master Thesis. Postgraduate Program, State University of Malang.

[4] Mangesa, R., I. Irsan. 2020. Efektifitas fraksi aktif methanol daun sirih merah (Piper crocatum) yang berpotensi sebagai antibakteri Salmonellas typhi: (the effectiveness of methanol active fraction of red better leaves [Piper crocatum] that potential as an antibacterial Salmonellas typhi). Uniqbu Journal of Exact Sciences. 1(2). 40-45.

[5] Juliantina, R.F., M.D.A., Citra, B. Nirwani, T. Nurmasitoh, E.T. Bowo, 2009. Manfaat sirih merah sebagai agen antbakterial terhadap bakteri gram positif dan gram negatif. Jurnal Kedokteran dan Kesehatan Indonesia. 1(1). 12-20.

[6] Zulharini, M., Sutejo, I.R., Fadliyah, H. and Jenie, R.I., 2018. Methanolic extract of red betel leaves (Piper crocatum Ruiz \& Pav) performs the cytotoxic effect and antimigration activity toward metastatic breast cancer. Indones. J. Cancer Chemoprevention. 8(3). 94-100.

[7] Iqbal, N., N. Iqbal. 2014. Human epidermal growth factor receptor 2 (HER2) in cancers: overexpression and therapeutic implications. Mol. Biol. Int. 852748.

[8] Huang, H. 2018. Matrix metalloproteinase-9 (MMP-9) as a cancer biomarker and MMP-9 biosensors: recent advances. Sensors. 18(10). p.3249.

[9] Wang, X., Y. Lin, 2008. Tumor necrosis factor and cancer, buddies or foes? Acta Pharmacol. Sin. 29(11). 1275-1288.

[10] Krieger, E., G. Vriend. 2015. New ways to boost molecular dynamics simulations. J. Comput. Chem. 36(13). 996-1007.

[11] Masuda, M. 2019. Hunting hidden pieces of signaling pathways in hepatocellular carcinoma. Hepatobiliary Surg. Nutr. 8(1). 74.
[12] Adam, K., J. Lesperance, T. Hunter, P.E. Zage. 2020. The potential functional roles of NME1 histidine kinase activity in neuroblastoma pathogenesis. Int. J. Mol. Sci. 21(9). 3319.

[13] Liu, X., Y. Zhang, Y. Wang, M. Yang, F. Hong, S. Yang. 2021. Protein phosphorylation in cancer: role of nitric oxide signaling pathway. Biomolecules. 11(7). 1009.

[14] Daina, A., O. Michielin, V. Zoete. 2017. SwissADME: a free web tool to evaluate pharmacokinetics, drug-likeness, and medicinal chemistry friendliness of small molecules. Sci. Rep. 7(1). 1-13.

[15] Bare, Y., D.R.T. Sari, Y.T. Rachmad, G.C. Krisnamurti, A. Elizabeth, A. Maulidi. 2019. In silico insight the prediction of chlorogenic acid in coffee through Cyclooxygenase-2 (COX2) Interaction. Biogenesis: Jurnal IImiah Biologi. 7(2). 100-105.

[16] Wang, L., X. Zhi, Y. Zhu, Q. Zhang, W. Wang, Z. Li, J. Tang, J. Wang, S. Wei, B. Li, J. Zhou. 2015. MUC4-promoted neural invasion is mediated by the axon guidance factor Netrin-1 in PDAC. Oncotarget. 6(32). 33805.

[17] Rossi, A.F.T., J.C. Contiero, F. da Silva ManoelCaetano, F.E. Severino, A.E. Silva. 2019. Upregulation of tumor necrosis factor- $\alpha$ pathway survival genes and the receptor TNFR2 in gastric cancer. World J. Gastrointest. Oncol. 11(4). 281.

[18] Fusani, L., D.S. Palmer, D.O. Somers, I.D. Wall, 2020. Exploring ligand stability in protein crystal structures using binding pose metadynamics. J. Chem. Inf. Model. 60(3), 1528-1539.

[19] Wibowo, S., S. Widyarti, A. Sabarudin, D.W. Soeatmadji, S.B. Sumitro, 2019. The role of astaxanthin compared with metformin in preventing glycated human serum albumin from possible unfolding: a molecular dynamic study. Asian J. Pharmaceut. Clin. Res. 12(9). 276-282. 